\title{
ATOS DE CONCENTRAÇÃO ECONÔMICA ALÉM-FRONTEIRAS: INSTRUMENTALIDADE DA COOPERAÇÃO JURÍDICA NO DIREITO INTERNACIONAL DA CONCORRÊNCIA
}

\author{
Nicole Rinaldi de Barcellos* \\ Tatiana Bruhn Parmeggiani Gomes ${ }^{* *}$
}

Resumo: Este estudo objetiva investigar os atos de concentração entre empresas à luz do direito internacional da concorrência, especialmente quanto à coordenação das atividades das autoridades concorrenciais. $\mathrm{O}$ estudo foi dividido em duas partes. $\mathrm{Na}$ primeira seção analisase como a teoria define os atos de concentração que envolvam mais de uma jurisdição. $\mathrm{Na}$ segunda, estudam-se os aspectos jurídicos da cooperação internacional no direito da concorrência e as decisões do Conselho Administrativo de Defesa Econômica (CADE) no controle de condutas. Adota-se o método dedutivo. Conclui-se que a cooperação jurídica internacional é o principal instrumento para a convergência das práticas das autoridades concorrenciais.

Palavras-chave: Direito internacional da concorrência; Atos de concentração; Controle de estruturas; Conselho Administrativo de Defesa Econômica; Cooperação internacional na defesa da concorrência.

\section{ECONOMIC CONCENTRATION ACTS BEYOND BORDERS: INSTRUMENTALITY OF LEGAL COOPERATION IN INTERNATIONAL COMPETITION LAW}

\begin{abstract}
This study aims to investigate the acts of concentration in the light of international competition law, especially regarding the coordination of activities between competition authorities. The study was divided in two parts. In the first section we analyze how the theory defines concentration acts that involve more than one jurisdiction. In the second section we analyze the legal aspects of international cooperation in competition and the decisions of the Conselho Administrativo de Defesa Econômica (CADE). We adopt the deductive method. We conclude that international legal cooperation is the main instrument for the convergence of the practices of competition authorities.
\end{abstract}

Keywords: International competition law; Concentration acts; Structures regulation; Administrative Council for Economic Defense; International cooperation in competition law.

\footnotetext{
${ }^{*}$ Professora Substituta na Universidade Federal do Rio Grande do Sul (UFRGS), em Porto Alegre. Doutoranda e Mestre em Direito Internacional no Programa de Pós-Graduação em Direito da UFRGS. Endereço postal: Rua Casemiro de Abreu, 125, apto. 603, Bairro Rio Branco, Porto Alegre/RS, CEP 90.420-001. Endereço eletrônico: nicoledebarcellos@gmail.com

${ }^{* *}$ Professora do Instituto Brasileiro de Ensino, Desenvolvimento e Pesquisa (IDP), em Brasília. Doutoranda e Mestre em Direito Internacional pela Universidade Federal do Rio Grande do Sul (UFRGS). Endereço postal: CCSW 1, lote 2, apto. 510, Setor Sudoeste, Brasília/DF, CEP 70.680-150. Endereço eletrônico: tatibruhn@hotmail.com
} 


\section{INTRODUÇÃO}

O presente artigo debruça-se sobre a análise dos atos de concentração econômica que operam além-fronteiras, os também chamados atos de concentração multijurisidicionais. Justifica-se a abordagem do tema, especialmente em sua relação com a cooperação da cooperação jurídica internacional, pela significativa atualidade e importância das discussões que este tem despertado. Contemporaneamente, identifica-se o fenômeno de mundialização das operações econômicas, que, se olhado sob o viés do direito internacional da concorrência, tem como consequências o aumento das práticas relevantes ao comércio internacional e à sua restrição, contraposto à ausência de um quadro normativo que afaste os efeitos atos dos mercados (MARQUES, 2006, p. 331).

No Brasil, o tema dos atos de concentração econômicas multijurisdicionais passou por recente transformação, tendo em vista a promulgação de uma nova lei de concorrência. De acordo com a atualização legislativa imposta pela Lei 12.529/11 (BRASIL, 2011), os atos de concentração passam por uma avaliação a priori e não mais a posteriori como de praxe na égide da legislação dos anos 90, a saber a Lei 8.884/94 (BRASIL, 1994). Mesmo as concentrações econômicas que ocorram entre empresas estrangeiras devem ser notificadas ao Conselho Administrativo de Defesa Econômica (CADE) quando afetarem o mercado brasileiro.

Com efeito, foi noticiada recentemente no Brasil a aquisição Twenty-First Century Fox pela The Walt Disney Company, que traz como pano de fundo o acordo sobre a venda e transmissão do canal esportivo Fox Sports. Alude-se que embora as partes tenham se esforçado para cumprir a determinação, a venda não foi concretizada no tempo estipulado, sofrendo inclusive embargos pelos atrasos ocasionados pela pandemia da Covid-19. Sendo assim, justificou-se a revisão do corrente caso pelo CADE. Colaciona-se que a discussão envolvendo este ato de concentração se pauta nas práticas contratuais das operadoras de televisão por assinatura, observando se estas são isônomicas ou não. Na mesma toada, debatese também acerca da distribuição dos canais esportivos às tais operadoras televisivas.

No intuito de analisar esta recente casuística afeita ao Direito da Concorrência brasileiro, perpasse-se por questões relevantes. Afinal de contas, há possibilidade de uma empresa com elevada participação de mercado controlar a oferta de determinado produto, influenciando nos preços e no mercado de atuação? Tal provocação endereçada por Mario Gomes Schapiro e Fabiana Mesquita Bacchi (2013, p. 49-96) vai ao encontro do objeto 
investigativo deste artigo, uma vez que o Caso Fox/Disney em análise no Tribunal do CADE ditará quais são as restrições a serem observadas como condição para a validade do ato.

Resta-nos salientar que o presente caso que está sob análise da autarquia federal brasileira provocou nada mais, nada menos de 25 jurisdições diferentes, exigindo-se a cooperação jurídica internacional entre países e órgãos de concorrência ao redor do globo. Neste passo, busca-se responder: qual a questão em voga envolvendo atos de concentração multijurisdicionais? Uma vez que estamos falando de conflitos que provocam uma possível aplicação de variados regramentos nacionais de defesa da concorrência.

Para tanto, optou-se nesta pesquisa pela adoção do método de abordagem indutivo, a partir de premissas mais amplas, inseridas num diálogo sistêmico de complementaridade entre o Direito da Concorrência pátrio e as previsões em âmbito do Direito Internacional da Concorrência, sustentado pela análise de um ato prático de concentração multijurisicional que está sob os cuidados do CADE, com potencial de lançar prospecções futuras acerca da matéria.

Considerando-se que o estudo se dedica à análise da teoria e da prática envolvendo os atos de concentração multiconectados, na primeira seção analisa-se como a teoria define os atos de concentração que envolvam mais de uma jurisdição, a partir da delimitação conceitual pela doutrina e das regras constantes no ordenamento jurídico pátrio. Na segunda seção estudam-se os aspectos jurídicos da cooperação bilateral no direito da concorrência, para então realizar uma análise das decisões do CADE nesse tema.

\section{DEFINIÇÃO E REGULAMENTAÇÃO DOS ATOS DE CONCENTRAÇÃO ECONÔMICA MULTICONECTADOS}

Esboça-se neste tópico algumas delimitações conceituais albergadas pela legislação vigente. Cumpre por hora analisar os desenhos normativos com enfoque no fenômeno das concentrações conectadas internacionalmente. Sabe-se, apoiando-se nas palavras de Marianne Mendes Webber, que a vocação do Direito da Concorrência se encontra na regulação de práticas ocorridas dentro dos territórios dos Estados, denotando uma aplicação territorial limitada (2015, p. 40). Todavia, ainda sob à óptica da autora, com a intensificação da globalização econômica, as atividades empresariais apresentam-se cada vez mais em ações multijurisdicionais que afetam os interesses de vários Estados (2015, p. 40). Com base nisso, 
o presente tópico inicia-se pela formulação de delimitações conceituais (ponto 2.1), seguida da investigação sobre a regulamentação no Brasil.

\subsection{Delimitações conceituais - o que são atos de concentração econômica multiconectados?}

Augusto Jaeger Junior refere que o Direito da Concorrência é tradicionalmente dirigido às práticas ocorridas dentro do território de um Estado (JAEGER JUNIOR, 2008), o que é consentido pelo entendimento explorado por Marianne Mendes Webber à luz do caráter territorial e de expressão de soberania afeito à jurisdição (WEBBER, 2015). Por outro lado, as atividades das empresas, na forma como são concebidas hoje, não se mostram limitadas pelas fronteiras estatais, ou seja, elas assumem características transfronteiriças (JAEGER JUNIOR, 2008, p. 33-36). Sendo assim, tal realidade está em conflito com os limites territoriais dos Estados e com o âmbito de aplicação dos seus direitos (JAEGER JUNIOR, 2008, p. 33-36)

Evidente tal paradoxo, se faz necessário recorrer ao recorte de inserção do Direito Internacional da Concorrência que reconhece o desejo de todos os Estados atingidos por essas limitações à concorrência em regular as atividades limitadoras, ao passo que, produzem efeitos em um ou mais de um Estado. Sobre isso, An Hertogen complementa ao versar que as ações em um Estado são inseparáveis dos efeitos no território de outro Estado (2015, p. 901926), reportando o precedente jurídico do Caso S.S Lotus, que ganhou guarida no Direito Internacional como premissa de efeitos jurisdicionais extraterritoriais.

O que está posto é a verificada tendência de naturalização de atos de concentração suportados por grandes empresas num fluxo contínuo que extrapola quaisquer fronteiras territoriais, porquanto, atos de concentração multiconectados. Recita-se, para tanto, a percepção de Erik Jayme neste sentido:

Em verdade, a globalização caracterizada pelo fato dos Estados não serem mais os centros do poder e da proteção da pessoa humana. Os Estados estão cedendo grande parte de seus poderes aos mercados. As regras de concorrência determinam a vida e o comportamento dos seres humanos. A existência de um mercado global permite fusões de grandes empresas, 
resultando em um poder econômico gigantesco, que deixa aberta a questão de proteção do indivíduo (2000, p. 20).

Sob esta tônica se aduz que a nova lei que regimenta o Sistema Brasileiro de Defesa da Concorrência resguarda o critério extraterritorial, isso devido ao atual contexto econômico, que mediante um processo de integração econômica e de globalização, hoje manifesto em todas as partes do mundo, tornou a atividade econômica homogênea, não se falando mais em um mercado interno exclusivo de empresas nacionais (PEREIRA; SOUZA; LIMA, 2018, p. 76). Sobre a realidade brasileira, o que se pode ver é uma forte ascendência das empresas estrangeiras em território nacional, desde a abertura das portas ao capital estrangeiro, no governo de Juscelino Kubitschek (PEREIRA; SOUZA; LIMA, 2018, p. 76).

Complementa esta construção Charles P. Kindleberger ao proferir que o comércio inter-regional e o comércio internacional se distinguem do resto da Economia, ao passo que, nestas questões o espaço adquire certa importância, ou seja, os bens e serviços se movimentam, afastando a ideia estática de uma economia nacional como um único ponto no espaço e as outras economias nacionais como diferentes pontos aproximados entre si (1968, p. 4-5).

Parte-se, nomeadamente, a estes contornos normativos que orbitam ao redor da sociedade e economia globalizada. Neste ínterim, Gesner Oliveira e Grandino Rodas assinalam que a preocupação do Direito da Concorrência é justamente analisar se os efeitos derivados de determinado ato de concentração serão ou não maléficos a um dado mercado relevante. De maneira simplificada, esta operação envolvendo dois ou mais agentes independentes economicamente realizam uma operação duradoura na sua estrutura empresarial ou forma de controle (SCHAPIRO; BACCHI, 2013, p. 49-96).

Por mercado relevante, entende-se:

Espaço no qual dois ou mais agentes privados, concorrentes entre si vão aplicar seus respectivos mecanismos e disputar consumidores. Podem se valer de diversos instrumentos, tais como campanhas publicitárias, pesquisa tecnológica para fins de baratear o custo operacional e melhorar a qualidade dos bens ofertados entre outros (PEREIRA; SOUZA; LIMA, 2018, p. 80).

Importante ressaltar que embora muitos atos de concentração de fato resultem em uma maior concentração de mercado, ato contínuo também geram diferentes benefícios como uma maior eficiência produtiva, como novos produtos e novas tecnologias (SCHAPIRO; 
BACCHI, 2013, p. 49-96). Nesta senda é que as atuações das autoridades de concorrência operam, neste sopesamento entre as concentrações razoáveis e as desarrazoadas. Incumbe o cuidado com essas práticas transfonteiriças para que a boa concorrência seja sempre o guia dessas relações.

\subsection{Ordenamento jurídico brasileiro - como são regulados os atos de concentração econômica no Brasil?}

Lançam-se estudos aos aportes normativos presentes nos diplomas legais brasileiros, buscando elucidar como estes atos de concentração são regulados no país. Como esclarecido anteriormente, os atos de concentração multijurisdicionais estão alocados no espectro do Direito Internacional da Concorrência, que é desprovida de uma legislação uniformizada, cabendo aos Estados através da sua consolidação legislativa sistemática balizar estas relações sob o prisma da lei nacional.

Sendo assim, o artigo $2^{\circ}$ da Lei 12.529/11 traz a seguinte redação:

Art. $2^{\circ}$ Aplica-se esta Lei, sem prejuízo de convenções e tratados de que seja signatário o Brasil, às práticas cometidas no todo ou em parte no território nacional ou que nele produzam ou possam produzir efeitos.

$\S 1^{\circ}$ Reputa-se domiciliada no território nacional a empresa estrangeira que opere ou tenha no Brasil filial, agência, sucursal, escritório, estabelecimento, agente ou representante.

$\S 2^{\circ}$ A empresa estrangeira será notificada e intimada de todos os atos processuais previstos nesta Lei, independentemente de procuração ou de disposição contratual ou estatutária, na pessoa do agente ou representante ou pessoa responsável por sua filial, agência, sucursal, estabelecimento ou escritório instalado no Brasil (BRASIL, 2011)

Conforme leitura do dispositivo supracitado, reforça-se o entendimento expresso que todas as condutas que tenham efeitos sob o território nacional, potencial ou efetivo, com caráter prejudicial à livre concorrência serão reprimidas por tal legislação desde que não haja um acordo ou tratado celebrado pelo Brasil em sentido contrário (PEREIRA; SOUZA; LIMA, 2018, p. 76).

Os atos de concentração são passíveis de controle administrativo exercido pelo CADE, conforme rito dos seguintes artigos, a saber 53 a 57 da legislação de 2011 (BRASIL, 2011): 
Art. 53. O pedido de aprovação dos atos de concentração econômica a que se refere o art. 88 desta Lei deverá ser endereçado ao Cade e instruído com as informações e documentos indispensáveis à instauração do processo administrativo, definidos em resolução do Cade, além do comprovante de recolhimento da taxa respectiva.

$\S 1^{\circ}$ Ao verificar que a petição não preenche os requisitos exigidos no caput deste artigo ou apresenta defeitos e irregularidades capazes de dificultar o julgamento de mérito, a Superintendência-Geral determinará, uma única vez, que os requerentes a emendem, sob pena de arquivamento.

$\S 2^{\circ}$ Após o protocolo da apresentação do ato de concentração, ou de sua emenda, a Superintendência-Geral fará publicar edital, indicando o nome dos requerentes, a natureza da operação e os setores econômicos envolvidos. Art. 54. Após cumpridas as providências indicadas no art. 53, a Superintendência-Geral:

I - conhecerá diretamente do pedido, proferindo decisão terminativa, quando o processo dispensar novas diligências ou nos casos de menor potencial ofensivo à concorrência, assim definidos em resolução do Cade; ou

II - determinará a realização da instrução complementar, especificando as diligências a serem produzidas.

Art. 55. Concluída a instrução complementar determinada na forma do inciso II do caput do art. 54 desta Lei, a Superintendência-Geral deverá manifestar-se sobre seu satisfatório cumprimento, recebendo-a como adequada ao exame de mérito ou determinando que seja refeita, por estar incompleta.

Art. 56. A Superintendência-Geral poderá, por meio de decisão fundamentada, declarar a operação como complexa e determinar a realização de nova instrução complementar, especificando as diligências a serem produzidas.

Parágrafo único. Declarada a operação como complexa, poderá a Superintendência-Geral requerer ao Tribunal a prorrogação do prazo de que trata o $\S 2^{\circ}$ do art. 88 desta Lei.

Art. 57. Concluídas as instruções complementares de que tratam o inciso II do art. 54 e o art. 56 desta Lei, a Superintendência-Geral:

I - proferirá decisão aprovando o ato sem restrições;

II - oferecerá impugnação perante o Tribunal, caso entenda que o ato deva ser rejeitado, aprovado com restrições ou que não existam elementos conclusivos quanto aos seus efeitos no mercado.

Parágrafo único. Na impugnação do ato perante o Tribunal, deverão ser demonstrados, de forma circunstanciada, o potencial lesivo do ato à concorrência e as razões pelas quais não deve ser aprovado integralmente ou rejeitado.

Vistos os dispositivos legais, Igor Voronkoff elucida as formas de atuação do CADE que se desdobram nas seguintes: preventiva, repressiva e de forma educacional (2014, p. 144179). O autor esclarece que diante de uma atuação preventiva, o CADE, por meio do controle de concentrações, analisa as operações que possam ter maior impacto no mercado e que possam afetar a livre concorrência, concedendo a autorização para a realização dessas 
operações. Por outro lado, quando atua em sua forma repressiva, o Conselho averigua as práticas que visem à dominação de mercados, eliminação da concorrência e aumento arbitrário dos lucros, instaura os processos, decide e aplica as penalidades cabíveis (2014, p. 144-179). Credita-se que o aspecto educacional do CADE deve-se, contudo, a sua atuação de vanguarda no zelo da livre concorrência e na atualização legislativa introduzida pela Lei de Concorrência (BRASIL, 2011) através de uma análise a priori dos atos de concentração, conduta esta que evita a dificuldade de reverter prejuízos causados.

Ana Frazão contextualiza a necessidade de uma regulação adequada. Ao ponto de trazer elementos históricos que justificam e explicam os comportamentos adotados na atualidade. Ela menciona que a partir da década de 80, especialmente a partir dos governos Thatcher e Reagan nos Estados Unidos da América, que o Direito da Concorrência e suas políticas estavam baseadas essencialmente em dois pilares: a desregulação e a desoneração tributária. A ideia que passou a ser difundida era a de que, quanto mais livres fossem os agentes econômicos, mais teriam incentivos para investir e mais investiriam, gerando todos os resultados positivos para a economia e a sociedade (2020, p.1-7).

Portanto, não é sem razão que, nesse contexto, o Direito Antitruste, em princípio, tendeu a se concentrar apenas na maximização total de riqueza (2020, p. 1-7). Todavia, contemporaneamente, quando se fala na regulação de atos de concentração multiconectados, as preocupações se voltam à necessidade de uma efetiva cooperação internacional para aplacar os efeitos da extraterritorialidade e o desenvolvimento de um sistema internacionalizado que possa endereçar as questões de política de concorrência atualmente vislumbradas (WISH, 2009, p. 470-471). Tal abordagem será desenvolvida com afinco no item a seguir.

\section{COOPERAÇÃO JURÍDICA INTERNACIONAL NO CONTROLE DE ESTRUTURAS COM INCLINAÇÃO MULTIJURISDICIONAL}

A cooperação jurídica internacional é um instrumento disponível às autoridades concorrenciais com fins de alcance de uma efetiva defesa da concorrência, tendo sido frequentemente utilizada nos casos que envolvam atos de concentração econômica multijurisdicionais (BARCELLOS, 2019, p. 170). David Sokol, ao analisar o fenômeno relativo ao que chama de monopolistas sem fronteiras, destacou que o direito internacional da 
concorrência passa por uma era dourada (gilded age) na qual a cooperação internacional entre as autoridades concorrenciais assume papel fulcral, em níveis jamais antes vistos (2007, p. 37 122). Não poderia ser diferente, para que as ordens jurídicas enfrentem a complexidade da análise dos atos de concentração multijurisdicionais, mostra-se necessária a cooperação entre as autoridades pares nas ordens jurídicas envolvidas.

Este tópico do estudo tem como objetivo investigar a cooperação jurídica internacional bilateral entre as autoridades concorrenciais como um instrumento para a análise dos atos de concentração multijurisdicionais. Para tal, será abordado no primeiro tópico como ocorre a cooperação internacional, assim como será demonstrada a sua instrumentalidade ao direito internacional da concorrência (ponto 3.1). No segundo tópico serão estudadas algumas decisões do CADE sobre o tema.

\subsection{Cooperação jurídica internacional e controle de estruturas - como atuam as autoridades concorrenciais?}

O direito internacional da concorrência é profundamente influenciado pelo processo de globalização econômica, de modo que mecanismos tradicionais de direito interno dos Estados não mais se mostram suficientes na regulação de empresas com atuação multijurisdicional, tampouco na regulamentação de economias entrelaçadas dos países (SILVA, 2007, p. 420-421). Caso tomados por consideração os modelos de âmbitos de aplicação das legislações de direito da concorrência nacionais ${ }^{1}$, observa-se que o princípio da territorialidade não mais oferece aos Estados respostas sobre os problemas complexos envolvendo os atos de concentração multijurisdicionais ${ }^{2}$.

\footnotetext{
${ }^{1}$ Augusto Jaeger Junior define que os modelos de aplicação das legislações concorrenciais nacionais são divididos em: (i) princípio da territorialidade estrita, verificado quando o Estado decide por aplicar a sua legislação apenas às práticas ocorridas dentro de seu território; (ii) princípio da pseudo-territorialidade, sistema intermediário entre o princípio da territorialidade estrita e a teoria do efeitos; (iii) teoria dos efeitos, segundo o qual as normas de determinado país são aplicáveis a práticas ocorridas em seu território, bem como aos efeitos destas que nele sejam verificados, considerando-se, então, os agentes presentes no local onde o ato gerou efeito; (iv) princípio da ponderação, com base na doutrina da cortesia internacional (comity). Os modelos são adotados simultaneamente pelos Estados (JAEGER JUNIOR, 2008, p. 61-68). Sobre o tema, ver: SCHWARTZ; BASEDOW, Restrictions on Competition, 1995, p. 31-91; NEREP, Extraterritorial Control of Competition under International Law, 1983, p. 20-22; BASEDOW, 1997, p. 124-163.

${ }_{2}^{2}$ Uma interpretação ampliativa do princípio da territorialidade estrita leva, inevitavelmente, à aplicação extraterritorial do direito da concorrência ocorre quando as leis de um Estado são aplicadas a pessoas, atos ou bens que se encontrem alheios ao seu território, em razão da ocorrência de fatos com inclinação multijurisdicional, que afetem direta ou indiretamente o mercado de outro país (CASTEL, 1983, p. 24; FARIA, 1990, p. 19-46; JAEGER JUNIOR; JORGE, 2019, p. 269-287).
} 
Com isso, os Estados passaram a adotar também o princípio da ponderação, que é o modelo segundo o qual devem ser considerados os interesses relevantes dos outros Estados na aplicação das legislações concorrenciais nacionais, com fundamento na doutrina da cortesia internacional (comity) (JAEGER JUNIOR, p. 68). É justamente nessa ideia de cortesia internacional que se fundou a cooperação jurídica internacional na defesa da concorrência, quando foi possível uma transição da aplicação unilateral do direito da concorrência, e, portanto, territorial, para a aplicação bilateral. Isto foi possibilitado pelo reconhecimento do princípio da ponderação na jurisprudência de muitos países (BASEDOW, 1997, p. 143; GUZMAN, 2011).

Mahrer Dabbah destaca que a cortesia internacional se refere à mútua civilidade demonstrada pelas partes por meio de boas maneiras recíprocas e moderação, além de autocontrole pelo Estado, considerando-se os interesses relevantes dos demais Estados na aplicação de sua legislação (2003; 2011, p. 287). A cortesia encontra-se no âmago dos acordos de cooperação internacional para a defesa da concorrência, tendo em vista que eles têm como finalidade material de promover a cooperação e a coordenação entre as diferentes autoridades concorrenciais (WEBBER, 2015, p. 142). Nos atos de concentração, tal perspectiva tem os efeitos positivos de evitar a divergência das decisões das autoridades concorrenciais nacionais, assim como de reduzir custos para as partes envolvidas.

Nesse cenário, as autoridades de concorrência assumem um papel de protagonismo, pois são instituições administrativas essenciais para a cooperação internacional neste ramo e devem lidar com situações complexamente internacionalizadas (BARCELLOS, 2019, p. 4). A autoridade concorrencial é o órgão administrativo do Estado especializado em endereçar a responsabilidade sobre temas relacionados à defesa da concorrência, cuja organização pode ocorrer de quatro maneiras distintas, a saber, em uma autoridade única, como no Brasil, em mais de uma autoridade em relação horizontal, como nos Estados Unidos da América, em diversas autoridades em relação vertical, como na União Europeia, e na divisão das competências entre autoridades de concorrência e autoridades regulatórias setoriais (TERECHTE, 2011, p. 49).

Nesse cenário, destaca-se a importância do CADE no Brasil, que atua na função de autoridade de concorrência brasileira, e também na função de autoridade central para a 
cooperação internacional em matéria concorrencial ${ }^{3}$. A instituição de uma autoridade central é determinante no processamento eficiente de solicitações nacionais ou estrangeiras, pois a sua instituição constitui medida voltada à modernização dos procedimentos de promoção da justiça internacional (MCCLEAN, 2002, p. 28). Caso considerados os atos de concentração multijurisdicionais, a centralização das atividades no CADE permite uma coordenação das atividades de aplicação da lei com relação às demais autoridades.

No Brasil, a cooperação internacional em matéria concorrencial entre as autoridades deve apresentar uma das três possíveis fontes: (i) os tratados, acordos ou convênios internacionais; (ii) a lei doméstica; ou (iii) a reciprocidade (BRASIL, 2017). Nesse cenário, destacam-se especialmente os acordos bilaterais de cooperação jurídica internacional, que podem conter em seu objeto a cortesia negativa ou positiva, a notificação sobre os casos trocada entre autoridades de defesa da concorrência, a busca e compartilhamento de informações, a cooperação e coordenação das atividades entre as autoridades de concorrência e a cooperação técnica (BARCELLOS, 2019, p. 25-38; WEBBER, 2015, p. 146-167; ZANETTIN, 2002, p. 71-76; PAPADOPOULOS, 2010, p. 127-144).

Eleanor M. Fox destaca que as autoridades de concorrência concorrenciais ao redor do mundo corresponderam aos desafios da globalização (2011, p. 266) ao valorizarem a cooperação administrativa para a concorrência. O CADE destaca-se nesse campo, tendo a sua jurisprudência refletido o mencionado entendimento, conforme passa-se a analisar a seguir.

\subsection{Casos sobre atos de concentração econômica multijurisdicionais no CADE - como é realizada a análise no Brasil?}

Como visto, o CADE é a autoridade de concorrência brasileira, assim como a autoridade central para a cooperação internacional em matéria concorrencial, de modo que compete ao tribunal nele inserido, o Tribunal Administrativo de Defesa Econômica, julgar os atos de concentração empresariais multijurisdicionais, utilizando a cooperação internacional.

\footnotetext{
${ }^{3}$ A cooperação jurídica internacional no CADE possui como marco regulatório publicação de dois instrumentos legislativos, o Decreto $n^{\circ} 7.738 / 12$, que aprovou a Estrutura Regimental do CADE, e a Resolução do CADE $\mathrm{n}^{\circ}$ 1/12, que instituiu o RICADE, hoje revogados e substituídos pelo Decreto 9.011/17 e a atual Resolução do CADE $n^{\circ} 22$, de 19 de junho de 2019, atualizado pela Emenda Regimental no 01/2020 de 02 de abril de 2020 (estabelece o Regimento Interno do CADE - RICADE), que mantém as competências para a cooperação internacional ao CADE e instituem, inclusive, uma assessoria internacional para o CADE, para auxiliar nos procedimentos na matéria.
} 
Nesse sentido, a cooperação aparece como um instrumento essencial para instruir e informar o processo de análise e de controle das estruturas empresarias, seja pelo compartilhamento de documentos ou pela coordenação da atuação entre diferentes autoridades. Nessa seara, a cooperação no CADE assume grande relevância após a promulgação da Lei 12.529/11, pois a partir dela foi adotada a análise prévia dos atos de concentração, de modo a fortificar os esforços de cooperação entre autoridades de defesa da concorrência na análise dos atos de concentração multijurisdicionais (2015, p. 192).

O primeiro caso a ser mencionado é da aquisição pela Dow Brasil S/A da empresa Rohm and Haas Química Ltda., ambas atuantes no mercado da indústria química e petroquímica, e sediadas no Brasil, mas constituídas e organizadas conforme a legislação de sua origem, norte-americana. Esse processo foi instaurado no CADE sob o $\mathrm{n}^{\mathbf{o}}$ 08012.007982/2008-07, sendo que à época da publicação do voto do Conselheiro-Relator do caso, em 25 de novembro de 2009, a operação de concentração já havia sido aprovada em sete jurisdições pelas autoridades de concorrência correspondentes, a saber África do Sul, Turquia, Canadá, Taiwan, China, México e União Europeia ${ }^{4}$.

No caso, foi ressaltada pelo CADE a aprovação com restrições pela Federal Trade Comission (FTC) dos Estados Unidos da América, que condicionava a operação à venda de alguns ativos que envolviam a alienação da carteira de clientes da América do Sul ${ }^{5}$. A adoção da decisão da agência concorrencial norte-americana como fundamento da análise do caso no Brasil, demonstra uma coordenação das decisões e denota a relevância da cooperação internacional para a concorrência. Entretanto, observa-se que houve uma adoção unilateral da decisão pela autoridade de concorrência brasileira.

Da análise da decisão do CADE, verifica-se que com fundamento na decisão da FTC, a empresa Dow ficou obrigada a vender ativos que repercutiam no mercado brasileiro, além de de assinar acordo de venda de ativos, reconhecendo-se que não haveria no Brasil a sobreposição de mercado de três dos cinco produtos analisados. Após a análise das condições para a permissão da fusão, a operação de concentração foi aprovada sem restrições no Brasil.

Em caso semelhante que tratou da aquisição da empresa Wyeth pela Pfizer Inc., analisado pelo CADE em processo administrativo registrado sob o ${ }^{\circ}$ 08012.00157/2009-71, também houve uma adoção unilateral das decisões provenientes das autoridades estrangeiras,

\footnotetext{
${ }^{4}$ Tal posicionamento pode ser encontrado no voto do Conselheiro Relator no Processo no ${ }^{\circ}$ 08012.007982/200807.

${ }^{5}$ Sobre a adoção da decisão da FTC, veja-se o parecer da SEAE no processo no 08012.007982/2008-07, p. 12/16.
} 
pois, à época da decisão nacional as determinações estrangeiras já haviam sido publicadas e a operação de concentração havia sido concluída no exterior.

Segundo destacado nas decisões do CADE, as mencionadas empresas firmaram um contrato para concretização da operação de concentração em 25 de janeiro de 2009. A operação foi notificada ao CADE em 13 de fevereiro de 2009, porém, até surgir o voto do relator do processo administrativo no Brasil, datado de 12 de setembro de 2012, o referido ato já tinha recebido pareceres favoráveis na Colômbia, na Nova Zelândia, no Paquistão, na Sérvia, em Taiwan e na Turquia, tendo sido aprovado, contudo, com restrições no Canadá, no México, nos EUA e na China.

As duas mencionadas decisões datam do período anterior à entrada em vigor da Lei $\mathrm{n}^{\text {o }}$ 12.529/11 e denotam uma passividade brasileira na análise dos atos de concentração multijurisdicionais, pela adoção as decisões já proferidas por órgãos estrangeiros. A partir da mais recente lei concorrencial brasileira esse cenário sofreu profundas modificações, pois foi alterada a forma como os atos são submetidos ao CADE, pela adoção da análise e controle prévio de concentrações econômicas (CARVALHO, 2012, p. 37). Foi possível, então, uma verdadeira coordenação das atividades das autoridades concorrenciais.

Nessa nova era da análise dos atos de concentração, destaca-se o caso da aquisição de controle da Mach pela empresa Synverse, ambas baseadas no exterior, registrada no Processo $n^{\circ}$ 08700.006437/2012-13 do CADE. As empresas atuam no setor de serviços de tecnologia em telecomunicações, sendo que a aquisição de controle em questão foi aprovada com restrições pelo CADE, tendo em vista que a operação envolvia mercados extremamente concentrados de GSM data clearing, sistema utilizado pelas operadoras para a cobrança de roaming e Near Real Time Roaming Data Exchange (NRTRDE), serviço que permite a detecção de fraudes de roaming. Segundo a decisão do CADE, a operação econômica foi condicionada à assinatura de um Acordo em Controle de Concentração (ACC) pelos notificantes.

Aqui, importa destacar que esse ato foi à análise das autoridades concorrenciais no Brasil e na União Europeia, o que permitiu uma troca de informações e a sincronização das etapas de investigação nos dois órgãos ${ }^{6}$. Assim, o CADE tomou a decisão de aprovação em 22 de maio de 2013, que foi seguida pela decisão europeia, nesse mesmo sentido, em 29 de maio de 2013. Demonstram-se com o caso os grandes avanços alcançados, tendo em vista que

\footnotetext{
${ }^{6}$ Sobre o tema, ver o voto do Conselheiro-Relator no Processo no ${ }^{\circ}$ 08700.006437/2012-13.
} 
a instituição da análise prévia possibilitou o julgamento dos atos de forma simultânea pelas autoridades de concorrência, debatendo-se soluções de forma coordenada, permitindo-se um diálogo entre as autoridades concorrenciais no controle de concentrações.

Também se destaca o caso da fusão das empresas Munksjö AB e Ahlstrom Corporation, ambas de nacionalidade estrangeira, notificada no CADE em 19 de novembro de 2012, registrada no CADE sob o $\mathrm{n}^{\mathrm{o}}$ 08700.009882/2012-35. O referido ato resultaria em uma elevada concentração no mercado de papel decorativo pré-impregnado (PRIP). Na decisão do CADE, destacou-se que as empresas propuseram ao órgão a assinatura de um Acordo em Controle de Concentração para a venda de ativos da Ahlstrom, cuja aprovação foi recomendada pela Superintendência-Geral do CADE, e confirmada pelo Tribunal em 22 de maio de 2013. Como no caso anterior, a operação de concentração foi simultaneamente submetida à análise na União Europeia, e foi objeto de importante cooperação entre as autoridades concorrenciais, tendo a decisão europeia sido mesmo sentido da brasileira, em 24 de maio de 2013. Vinicius Marques de Carvalho e Paulo Burnier da Silveira informam que as autoridades de concorrência debateram entre si para encontrar uma solução adequada ao caso concreto, sob o manto da legislação concorrencial brasileira (2013, p. 102).

Da análise das decisões proferidas pelo CADE nos atos de concentração multijurisdicional fica claro que a promulgação da Lei 12.529/11, com a análise prévia dos atos de concentração, levou à intensificação da cooperação entre o CADE e as autoridades pares (WEBBER, 2015, p. 196). Ademais, a institucionalização do CADE como autoridade central permitiu a criação de instrumentos de direito interno aptos a facilitar a cooperação em matéria concorrencial (ARANOVICH, 2012, p. 132).

Anu Bradford destaca que a cooperação tende a ser mais eficiente nos casos de análise de concentrações, caso fosse feita uma comparação com relação aos cartéis, à medida que as notificantes têm incentivos para assinar acordos de renúncia de confidencialidade, com fins de que seja acelerada a autorização da operação econômica por parte das autoridades (2011, p. 323). Outro ponto importante destacado é que maior grau de autonomia influencia positivamente o aumento da efetividade da implementação da legislação de defesa da concorrência (GAL, 2002, p. 6-10).

A verdade é que a cooperação jurídica bilateral, como exemplificada, tem demonstrado que a análise dos atos de concentração multijurisdicional somente pode ser operacionalizada pela colaboração entre as autoridades concorrenciais, especialmente quanto 
à coordenação das atividades das autoridades na aplicação das legislações nacionais. Maher Dabbah destaca que não existe consenso sobre eficiência da cooperação na esfera bilateral (2011, p. 293), ainda que observe que na prática esta tem sido exitosa (2011, p. 293).

Se for retomado o caso prático citado na introdução desse estudo, observa-se, assim como nos casos anteriores, que a cooperação internacional é tomada em consideração. No caso da aquisição da Twenty-First Century Fox pela The Walt Disney Company, a operação foi notificada em 25 jurisdições, tendo sido o resultado da colaboração entre autoridades antitruste de diversas partes do mundo, especialmente na América Latina, com as autoridades concorrenciais do México e do Chile. Segundo Paulo Burnier da Silveira em seu voto:

\begin{abstract}
O diálogo entre as autoridades de defesa da concorrência em casos como esse tem se mostrado fundamental, em especial quando consideradas as possíveis consequências para os remédios adotados por cada país. Trata-se de mecanismo que permite uma maior qualidade nas análises empreendidas, efetividade de eventuais remédios, além da redução das chances de decisões contraditórias ou inconsistentes. Desde sua última reestruturação, o CADE teve diversas oportunidades de atuar em cooperação com outras jurisdições [...] o CADE foi capaz de coordenar remédios que atendessem tanto a preocupações comuns de diferentes jurisdições como a situações particulares à realidade do mercado brasileiro. Esta experiência acumulada nos últimos anos reflete-se no presente caso, demonstrando o amadurecimento institucional do CADE. Desta vez, a cooperação também se deu com diversas outras autoridades concorrenciais, como o Departamento de Justiça dos EUA (DoJ) e, sobretudo, com agências antitrustes latino-americanas como a Fiscalía Nacional Económica do Chile e a Federal Telecommunications Institute(IFT) e a Comisión Federal de Competencia Económica (COFECE), ambas do México (CADE, 2019).
\end{abstract}

Ainda segundo o Conselheiro em seu voto, no caso da jurisdição mexicana, a proveitosa cooperação internacional levou à negociação de um ACC com contornos muito similares à proposta brasileira (CADE, 2019). Dessa forma, esse caso corrobora o argumento de que a cooperação internacional é essencial no controle de atos de concentração empresarial multijurisdicionais, pois "há claros benefícios para os consumidores, sobretudo se pensarmos na maior probabilidade de um comprador de musculatura global, considerando os remédios estruturais requeridos por outras autoridades da concorrência da região latino-americana" (CADE, 2019).

Com isso, demonstra-se que a cooperação jurídica internacional em matéria concorrencial constitui uma relevante solução para resolver os conflitos decorrentes dos casos de atos de concentração multijurisdicionais, pois é uma solução realista e conectada à pratica (WEBBER, 2015, p. 213; BOTTA, 2009, p. 155). 


\section{CONSIDERAÇÕES FINAIS}

Este artigo teve como objetivo analisar os atos de concentração econômica multiconectados, isto é, aqueles que implicam na notificação em mais de uma jurisdição. Investigou-se como os atos de concentração multijurisdicionais são definidos e a instrumentalidade da cooperação jurídica internacional nessa seara, especialmente no que tange à legislação brasileira e à atuação do CADE.

Buscou-se identificar qual a questão em voga envolvendo atos de concentração multijurisdicionais, tendo em vista que estão relacionados a conflitos provocam uma possível aplicação de variados regramentos nacionais de defesa da concorrência. Como ponto de partida, tomou-se como exemplo o recente caso da aquisição da Twenty-First Century Fox pela The Walt Disney Company, no qual foi destacada a importância da cooperação jurídica internacional para o direito da concorrência.

Após analisar as delimitações conceituais e regulamentação dos atos de concentração multijurisdicionais, este estudo demonstra que a cooperação jurídica internacional é um instrumento necessário para a coordenação das atividades de aplicação das legislações domésticas na defesa da concorrência. Com base nos casos de análise de estruturas conduzidos pelo CADE, que é a autoridade concorrencial brasileira e autoridade central para a cooperação nesses temas, comprova-se que a cooperação jurídica internacional é o principal instrumento para a convergência das práticas das autoridades na análise dos atos de concentração multijurisdicionais, tendo em vista que proporciona que os diversos países se comuniquem acerca dos casos complexamente internacionalizados.

\section{REFERÊNCIAS}

ARANOVICH, Tatiana de Campos. Inovações na cooperação jurídica internacional para o Cade. Revista de Defesa da Concorrência, Brasília, n. 1, p. 124-148, 2013.

BRASIL. Lei $n^{o} 8.884$ de 11 de junho de 1994. Disponível em: <http://www.planalto.gov.br/ccivil_03/leis/18884.htm>. Acesso em: set. 2020.

BRASIL. Lei $n^{o} 12.529$ de 30 de novembro de 2011. Disponível em: <http://www.planalto.gov.br/ccivil_03/_ato2011-2014/2011/lei/112529.htm>. Acesso em: set. 2020. 
BRASIL. Decreto 9.011/17, de 13 de março de 2017. Disponível em: < http://www.planalto.gov.br/ccivil_03/_ato2015-2018/2017/decreto/D9011.htm>. Acesso em: 27 set. 2020.

BARCELLOS, Nicole Rinaldi de. Cooperação jurídica internacional na defesa da concorrência: convergência de instrumentos na cooperação entre autoridades concorrenciais. Belo Horizonte: Arraes, 2019.

BASEDOW, Jürgen. Souveraineté territoriale et globalisation des marchés: le domaine d'applications des lois contre les restrictions de la concurrence. Recueil des Cours, t. 264. La Haye: Académie de Droit Internatinal de la Haye, 1997, p. 124-163.

BOTTA, Marco. The Cooperation Between Antitrust Authorities of the Developing Countries: Why does it not Work? Case Study on Argentina and Brazil. Competition Law Review, v. 5, n. 2, 2009. Disponível em: < http:// clasf.org/browse-the-complrev/>. Acesso em: 22 set. 2020.

BRADFORD, Anu. International Antitrust Cooperation and the Preference for Nonbinding Regimes. In: GUZMAN, Antdrew T. (Org.). Cooperation, Comity and Competition Policy. New York: Oxford University Press, 2011, p. 319-344.

CASTEL, Jean-Gabriel. The extraterritorial effects of antitrust laws. Recueil des Cours, t. 179. Haia: Académie de Droit Internatinal de la Haye, 1983.

CARVALHO, Vinicius Marques de. Lei 12.529 de 30 de novembro de 2011. In: CORDOVIL, Leonor; CARVALHO, Vinicius Marques de; BAGNOLI, Vicente; ANDERS, Eduardo Caminati. Nova Lei de Defesa da Concorrência Comentada: Lei 12.529, de 30 de novembro de 2011. São Paulo: Revista dos Tribunais, 2012, p. 37.

CARVALHO, Vinicius Marques de; SILVEIRA, Paulo Burnier da. A cooperação internacional na defesa da concorrência. Revista de Direito Internacional, Brasília, v. 10, n. 1, p. 97-103, 2013.

COMISSÃO EUROPEIA. Caso COMP/M.6690 Syniverse/MACH. Disponível em: < http://ec.europa.eu/competition/mergers/cases/decisions/m6690_4017_2.pdf>. Acesso em: 27 set. 2020.

COMISSÃO EUROPEIA. Caso M.6576 Munksjö/Ahlstrom. Disponível em: $<\mathrm{http} / / /$ ec.europa.eu/competition/mergers/cases/decisions/m6576_20130524_20600_4231067 _EN.pdf>. Acesso em: 3 dez. 2015.

CONSELHO ADMINISTRATIVO DE DEFESA ECONÔMICA. Ato de Concentração $n^{o}$ 08700.004494/2018-53. Voto do Conselheiro Paulo Burnier da Silveira de 27 de fevereiro de 2019. Disponível em: < https://sei.cade.gov.br/sei/modulos/pesquisa /md_pesq_documento_consulta_externa.php?DZ2uWeaYicbuRZEFhBt-n3BfPLlu9u7ak QAh8mpB9yOcVK-n71Bwre7bTJYGLwRq9tJb100HRh87WxtBhK19dpmCaTT6P6Ep1ZH BehjUQZD553LNcUyAbILson1ISDNc\#_Toc2037574>. Acesso em: 27 set. 2020. 
CONSELHO ADMINISTRATIVO DE DEFESA ECONÔMICA. Resolução no 20, de 7 de junho de 2017. Disponível em: < http://www.cade.gov.br/assuntos/normas-e-legislacao/regimento-interno/novo-regimento-interno-do-conselho-adminstrativo-de-defesaeconomica-cade-07_nov-2017>. Acesso em: 24 set. 2020.

CONSELHO ADMINISTRATIVO DE DEFESA ECONÔMICA. Ato de Concentração Processo no 08012.007982/2008-07. Disponivel em: http://www.cade.gov.br/Default.aspx?b6778890968b9f748c9d6bcf60>. Acesso em: 27 set. 2020.

CONSELHO ADMINISTRATIVO DE DEFESA ECONÔMICA. Ato de Concentração Processo no 08012.001157/2009-71. Disponível em: < https://sei.cade. gov.br/sei/modulos/pesquisa/md_pesq_processo_exibir.php?KOXi3eEqJC73dCc3G_MH5w7 3G76i-vtXYDDG65Jr7vK4fhNNdRnnFDgAfJTIfRn8_ywCudV1gCNGrQiNgXFAcnUyDuwufh CTDXV-DyKZyiTniYfaliAJ6eo4qE8l2o6As5 >. Acesso em: 27 set. 2020.

CONSELHO ADMINISTRATIVO DE DEFESA ECONÔMICA. Ato de Concentração Processo no 08700.006437/2012-13. Disponível em: < https://sei.cade. gov.br/sei/modulos/pesquisa/md_pesq_processo_exibir.php?KOXi3eEqJC73dCc3G_MH5w7 3G76iv-tXYDDG65Jr7vK4fhNNdRnnFDgAfJTIfRn8_ywCudV1gCNGrQiNgXFAcndKiOJICH XuyIJ2cm7U- zjn7yS8iyJzde6WmHHj97hDFm >. Acesso em: 27 set. 2020.

CONSELHO ADMINISTRATIVO DE DEFESA ECONÔMICA. Ato de Concentração. Processo no 08700.009882/2012-35. Disponível em: < https://sei.cade. gov.br/sei/modulos/pesquisa/md_pesq_processo_exibir.php?2pXoYgv29q86Rn-fAe4ZUaXIR 3v7-gVxEWL1JeBRRtUgqOwvr6ZlwydlOIhRNSr2Q22lByVKByYDYwsa13_Jxp14yNFpgNXnb IuL78qN-LPYYiWblpBAal_vAy6HOWZ89>. Acesso em: 27 set. 2020.

DABBAH, Maher. Future Directions on Bilateral Cooperation: a Policy Perspective. GUZMAN, Andrew (Ed). Cooperation, Comity, and Competition Policy. Oxford: Oxford University Press, 2011, p. 287-299.

DABBAH, Maher. The internationalization of Antitrust Policy. Cambridge: Cambridge University Press, 2003.

FOX, Eleanor. Antitrust without borders: from roots to codes to networks. In: GUZMAN, Andrew (Ed). Cooperation, Comity, and Competition Policy. Oxford: Oxford University Press, 2011, p. 265-286.

FRAZÃO, Ana. Um Direito Antitruste para o século XXI, publicado em 26 de agosto de $2020 . \quad$ Jota. Disponível em: <https://www.jota.info/paywall?redirect_to=//www.jota.info/opiniao-e analise/colunas/constituicao-empresa-e-mercado/um-direito-antitruste-para-o-seculo-xxi-226082020>. Acesso em: 26 set. 2020.

GAL, Michal. Reality Bites (or Bits): The Political Economy of Antitrust Enforcement. New York University Law and Economics Working Papers, New York, n. 57, p. 6-22, 2002. 
GUZMAN, Andrew T. Cooperation, Comity, and Competition Policy. Oxford: Oxford University Press, 2011.

JAEGER JUNIOR, Augusto. Direito Internacional da Concorrência: entre perspectivas unilaterais, multilaterais, bilaterais e regionais. Curitiba: Juruá, 2008.

JAEGER JUNIOR, Augusto; JORGE, Mariana Sebalhos. O caso Intel: o impacto na evolução da teoria dos efeitos no direito da concorrência da União Europeia. Revista de Direito Internacional, Brasília, v. 16, n. 1, p. 269-287, 2019.

JAYME, Erik. Le droit international privé du noveau millénaire: la protection de la personne humaine face à la globalisation. Conférence prononcée le 24 juillet 2000. Haia: Académie de Droit International de la Haye, 2000. 40 p.

KINDLEBERGER, Charles P. Economia Internacional. Tomo I. 2. ed. São Paulo: Editora Mestre Jou, 1968.

MCCLEAN, John David. International Co-Operation in Civil and Criminal Matters. London: Oxford University Press, 2002.

MARQUES, Frederico do Valle. Direito Internacional da Concorrência. Rio de Janeiro: Renovar, 2006.

NEREP, Erik. Extraterritorial Control of Competition under International Law. Stockolm: PA Norstedt \& Söners Förlag, 1983, p. 20-22.

OCDE. Global Forum on Competition: Roundtable on Cross-Border Merger Control: Challenges for Developing and Emerging Economies: Contributions From Brazil, Dez. 2011. Disponível em: < http://www.oecd.org/officialdocuments/publicdisplaydocumentpdf /?cote=DAF/COMP/GF/WD(2010)83\&doclanguage=en>. Acesso em: 27 set. 2020 .

PAPADOPOULOS, Anestis S. The International Dimension of EU Competition Law and Policy. Cambridge: Cambridge University Press, 2010.

PEREIRA, Fabio da Silva; SOUZA, Ana Paula Marques de; LIMA, Renata Albuquerque. Sistema brasileiro de defesa da concorrência: implicações da Lei n ${ }^{\circ} 12.529 / 2011$ na defesa da concorrência. Rio de Janeiro: Lumen Juris, 2018.

SCHAPIRO, Mario Gomes; BACCHI, Fabiana Mesquista. Análise dos atos de concentração no Brasil - forma, função e o incrementalismo reformista do CADE. In: SCHAPIRO, Mario Gomes; CARVALHO, Vinicius Marques de; CORDOVIL, Leonor (Org.). Direito Econômico Concorrencial. 1. ed. São Paulo: Saraiva, 2013, v. 1, p. 49-96.

SCHWARTZ, Ivo E.; BASEDOW, Jürgen. Restrictions on Competition. In: LIPSTEIN, Kurt. International. Encyclopedia of Comparative Law. Private International Law. Volume III. Tübingen: Mohr Siebeck, 1995, p. 31-91. 
SILVA, Valéria Guimarães de Lima. Direito Antitruste: Aspectos Internacionais. Curitiba: Juruá, 2010.

SOKOL, David. Monopolists Without Borders: The Institutional Challenge of International Antitrust in a Global Gilded Age. Berkeley Business Law Journal, v. 4, Berkeley, p. 37-122, 2007.

TERHECHTE, Jörg Philipp. International Competition Enforcement Law Between Cooperation and Convergence. Berlin-Heidelberg: Springer Verlag, 2011. 96 p.

VORONKOFF, Igor. O novo sistema brasileiro de defesa da concorrência:estrutura administrativa e análise prévia dos atos de concentração. Revista de Defesa da Concorrência, Brasília, v. 2, n. 2, p. 144-179, 2014.

WEBBER, Marianne Mendes. Direito da Concorrência e Cooperação Jurídica Internacional. Belo Horizonte: Arraes Editores, 2015.

WISH, Richard. Competition Law. 6. ed. New York: Oxford University Press, 2009.

ZANETTIN, Bruno. Cooperation Between Antitrust Agencies at the International Level. Oregon: Hart Publishing, 2002. 